\title{
Atmospheric Mining in the Outer Solar System: Outer Planet Orbital Transfer and Lander Analyses
}

52 ${ }^{\text {th }}$ AIAA/ ASME/ SAE/ ASEE Joint Propulsion

Conference and Exhibit

Propulsion and Energy Forum

Salt Lake City, UT

Bryan Palaszewski

NASA Glenn Research Center

Cleveland $\mathrm{OH}$

July 2016 


\section{Introduction}

- Why atmospheric mining?

- Resource capturing: helium 3, hydrogen, helium.

- Orbital transfer vehicle (OTV), lander, factory sizing.

- System optimization(s) and issues.

- Observations.

- Concluding remarks. 


\section{In Situ Resource Utilization (ISRU)}

- In Situ Resource Utilization uses the materials from other places in the solar system to sustain human exploration

- Using those resources reduces the reliance on Earth launched mass, and hopefully reduces mission costs

- There are powerful capabilities to free humans from Earth 


\section{Why Atmospheric Mining?}

- Benefits:

- Large amount of matter to mine (hydrogen and helium 3)

- Potentially easier than mining regolith (dust) and rock

- Larger reservoir of materials not readily available in regolith (and in a gaseous state)

- Potential drawbacks

- Dipping deep into the gravity well of planets is expensive for propulsion systems

- Lifetime of systems

- Repetitive maneuvers

- Cryogenic atmospheric environments

- Long delivery pipelines 


\section{Uranus}

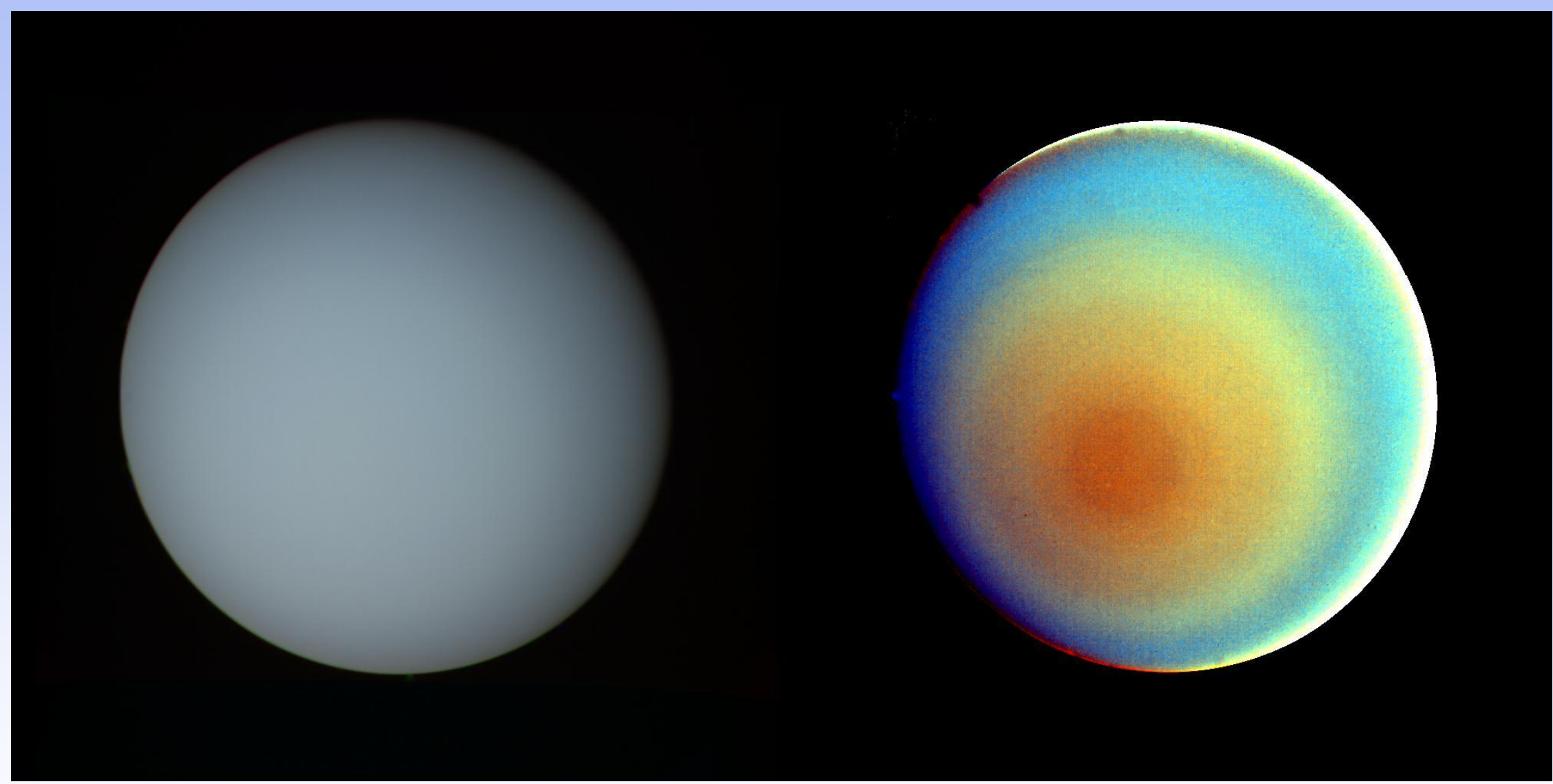

JPL 


\section{Neptune}

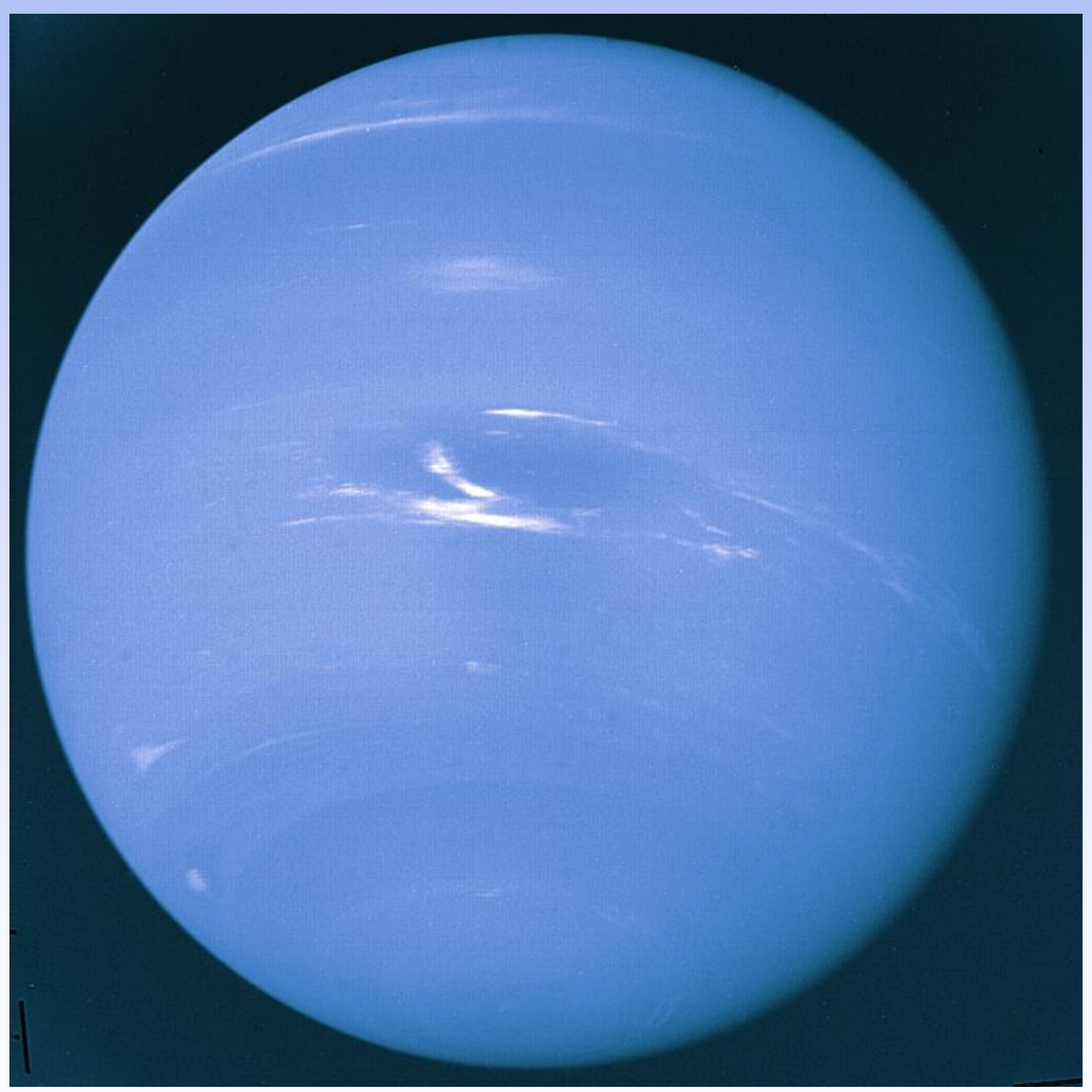

JPL 


\section{Outer Planet Atmospheres}

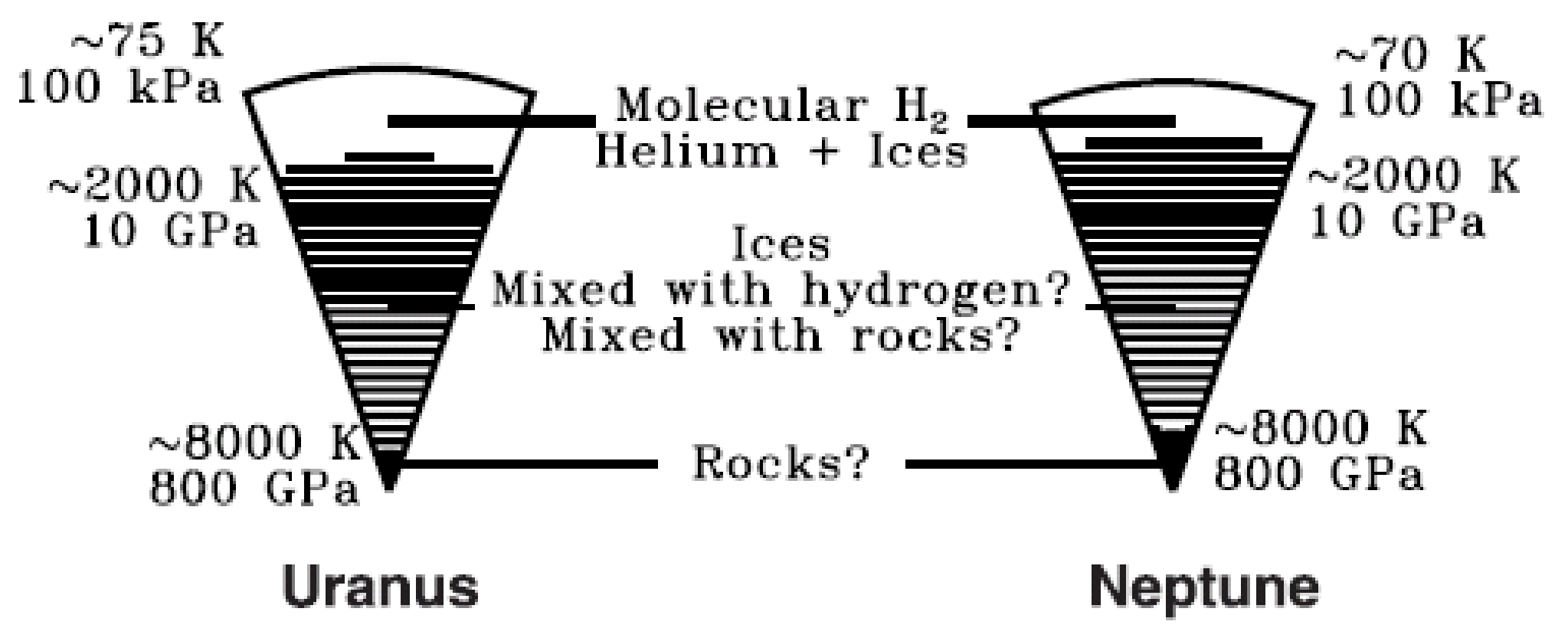

Tristan Guillot, "Interiors of Giant Planets Inside and Outside the Solar System." 


\section{Outer Planet Atmospheres and Wind Speeds}
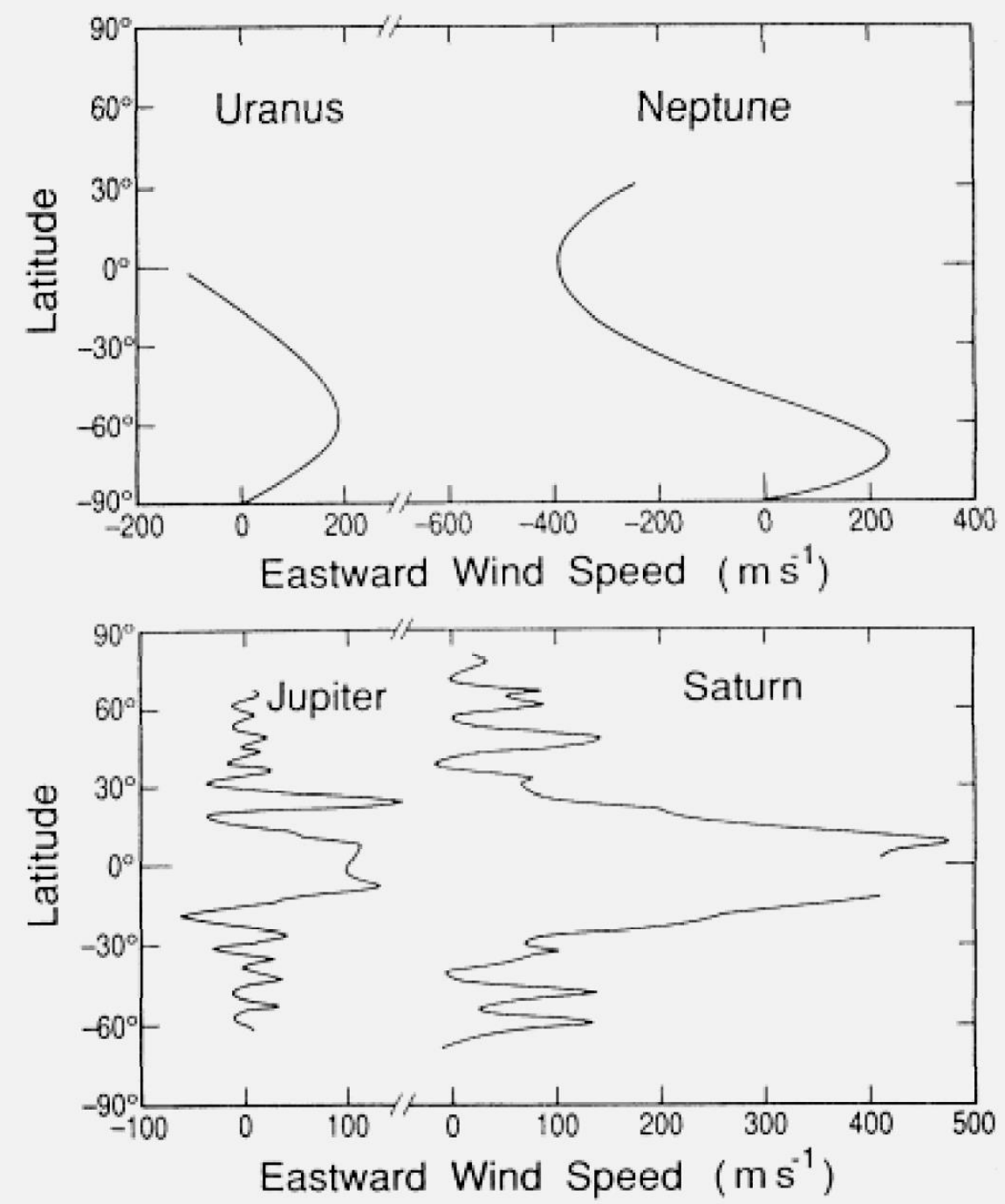

JPL, Ingersoll 


\section{Uranus Clouds Structures and "Weather"}

Uranus -

Outer Planet

Atmospheres

and

Wind Speeds

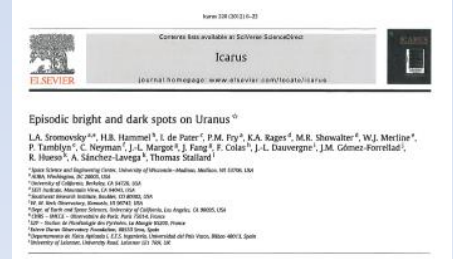

11 Nov 2011

\section{$H$ band}




\section{Orbital Velocities: $10 \mathrm{~km}$ altitude}

Planet Jupiter Saturn Uranus Neptune
Delta-V (km/s) 41.897 25.492 15.053 16.618
Comment BIG BIG More acceptable More acceptable 


\section{Cruiser Mining (1) Combined Miner and Aerospacecraft}

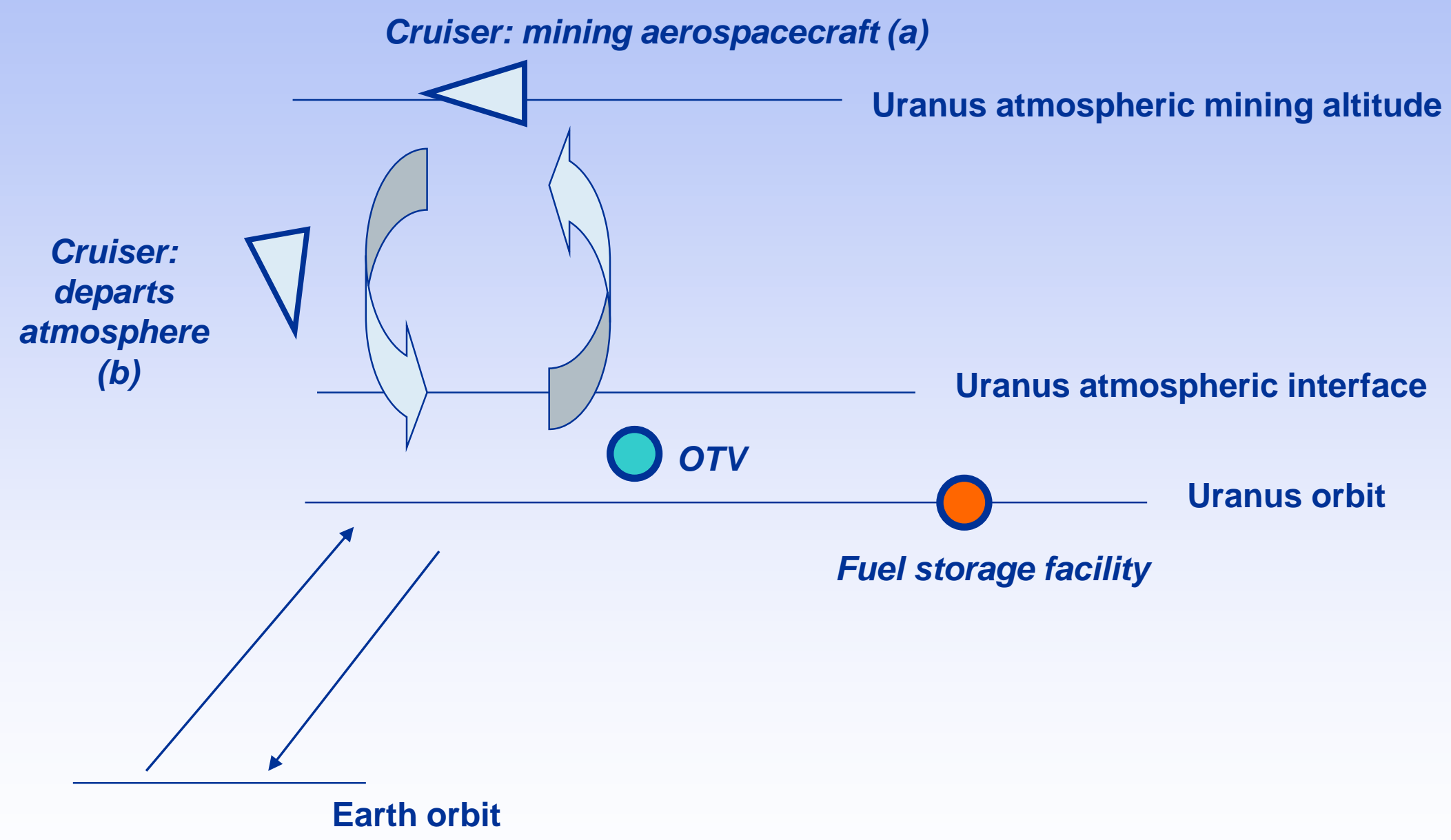




\section{Mining Scenarios and OTVs}

- Using cruiser aerospacecraft for mining in the atmosphere at subsonic speeds.

- Cruiser aerospacecraft then ascends to orbit, transferring propellant payload to orbital transfer vehicles (OTV).

- OTV will be the link to interplanetary transfer vehicle (ITV) for return to Earth.

- Moon bases for a propellant payload storage option was investigated. 


\section{AMOSS GCR Designs}

\section{CLOSED-CYCLE GAS CORE NUCLEAR ROCKET}

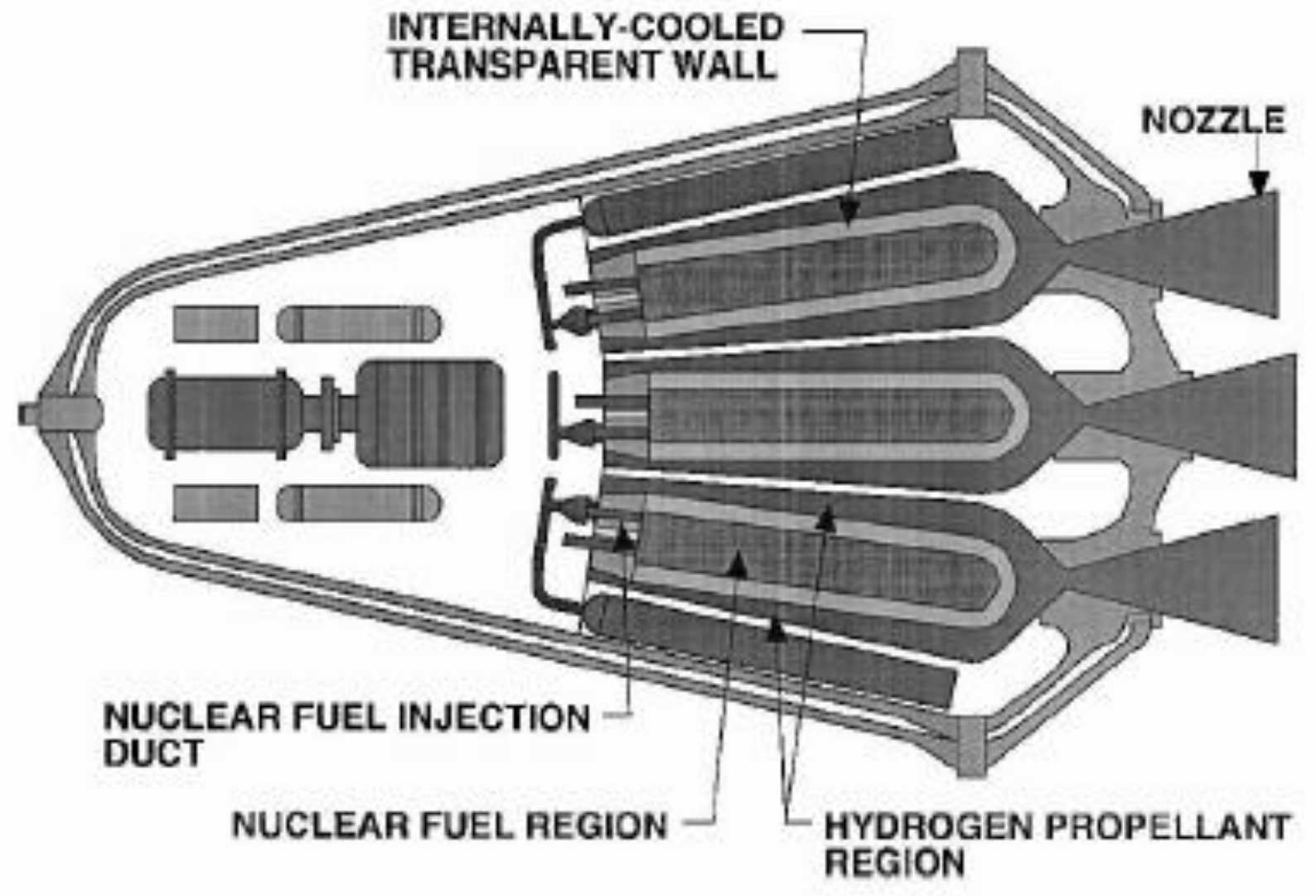




\section{Gas Core Design and Analysis Overview}

- Total aerospacecraft vehicle delta-V is $20 \mathrm{~km} / \mathrm{s}$.

- Single stage aerospacecraft.

- Gas core Isp values = 1800 and 2500 seconds

- Vehicles mass estimated over a broad range of dry masses.

- Dry mass (other than tankage) $=1,000,10,000$, 100,000 , and $1,000,000 \mathrm{~kg}$.

- Typical gas core dry mass $=80,000$ to $200,000 \mathrm{~kg}$.

- Tankage mass $=2 \%$ and $10 \%$ of propellant mass.

- Comparative case: solid core NTP Isp $=900$ seconds. 


\section{Gas core, Isp $=1,800 s$, Tankage $=2 \% M p$}

Nuclear Aerospacecraft,

OC Gas Core; 1,800-s Isp; 20-km/s delta-V capability;

1,000-kg payload

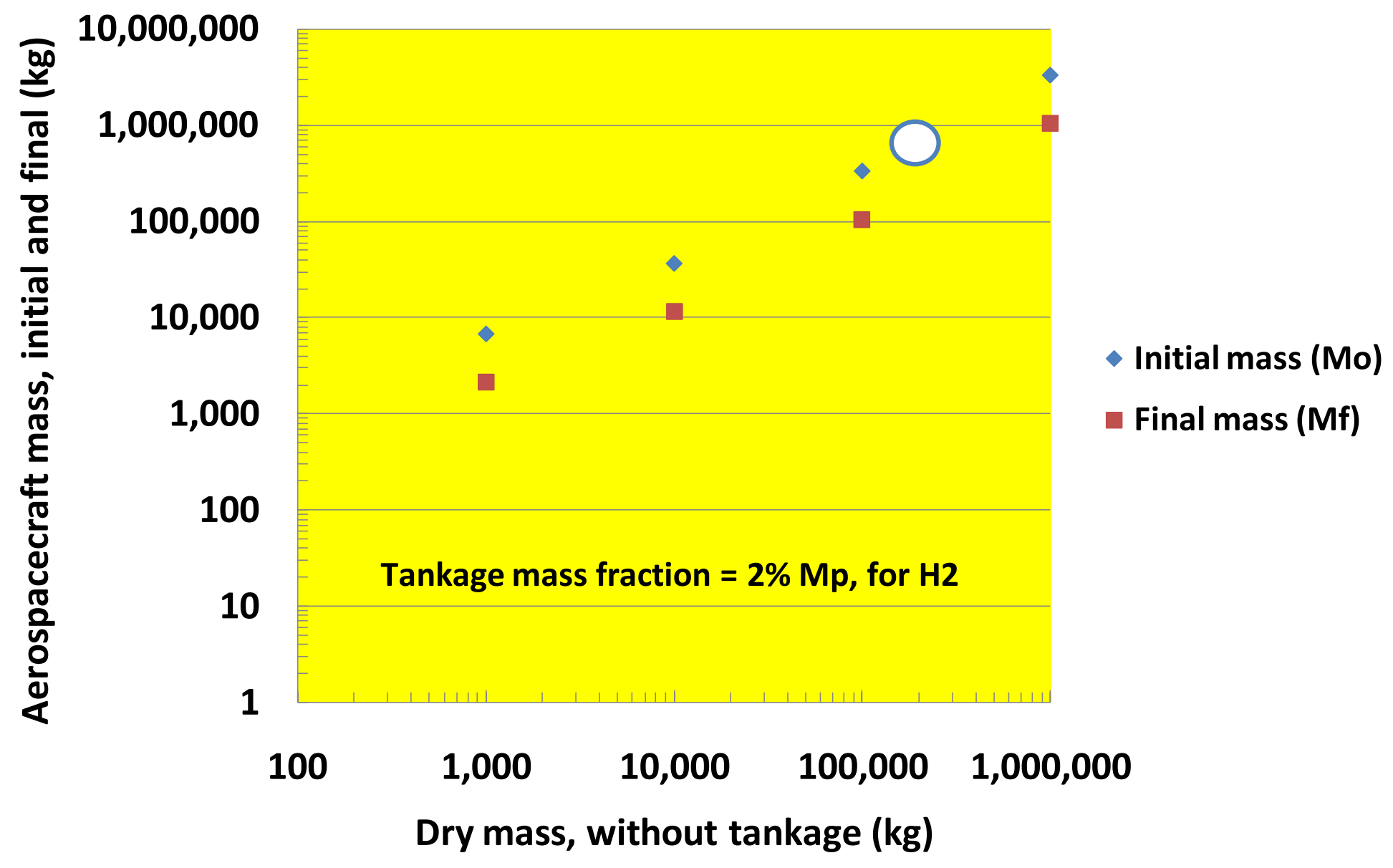




\section{AMOSS, Hydrogen Production at Uranus}

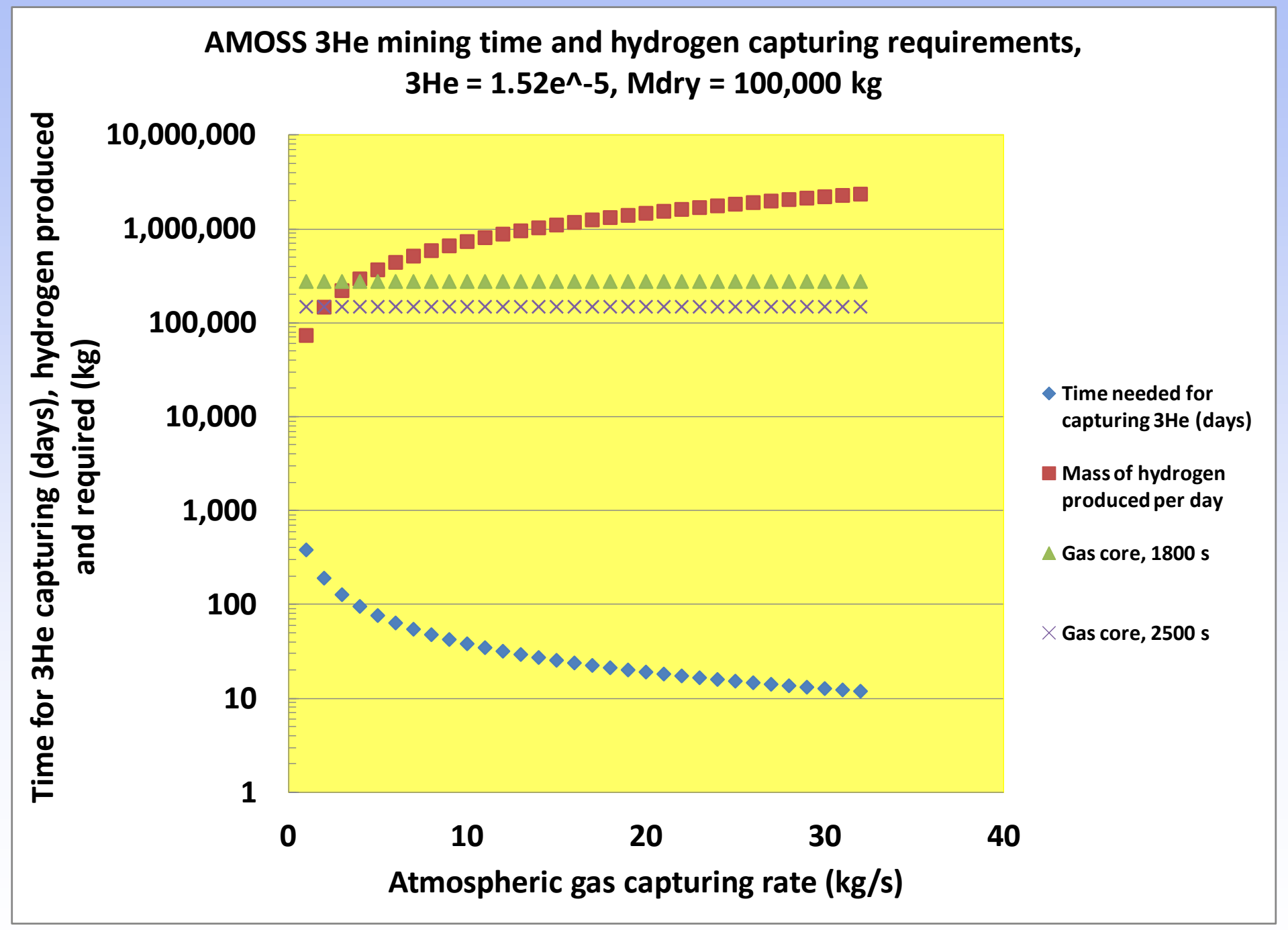


AMOSS Transportation Infrastructure and Implications - Uranus System Example

- Aerospacecraft (ASC) enter atmosphere and begins mining

- Lander(s) place the ISRU factories on moon(s).

- ISRU factory begins oxygen and hydrogen production.

- Lander is fueled with ISRU oxygen and hydrogen.

- Lander is loaded with hydrogen payload for OTV.

- OTV and lander rendezvous, OTV is fueled for round trip mission to Uranus.

- OTV picks up helium 3 from ASC.

- OTV delivers helium 3 to Lander (in moon's orbit).

- Lander refuels OTV and delivers helium 3 to ISRU factory (PPack). 


\section{OTV "optimizations"}

- Estimate OTV mass for all planet-to-moon round trip destinations.

- OTVs depart from $800 \mathrm{~km}$ planet altitude.

- OTVs arrive at moon(s), near moon's escape conditions (escape velocity).

- Will the smallest, or more distant moons provide the lowest OTV mass?

- Will the smaller or more distant moons require the longest OTV trip times? 


\section{Lander "optimizations"}

- Estimate mass of all ascent-descent moon "escape" round trip destinations.

- Include gravity losses; $20 \%$ of escape delta-V.

- Added margin on delta-V and propellant included for return of the full payload mass, in case of unsuccessful rendezvous. 


\section{Lander delta-V, Uranus' Moons}

\begin{tabular}{|l|r|r|r|}
\hline Moon & $\begin{array}{l}\text { Round-trip } \\
\text { delta-V (km/s) }\end{array}$ & $\begin{array}{l}\text { delta-V } \\
\text { Capability (km/s) }\end{array}$ & Sizing Category \\
\hline Miranda (UV) & 0.44 & 0.5 & a \\
\hline Ariel (UI) & 1.34 & 1.4 & b \\
\hline Umbriel (UII) & 1.24 & 1.3 & b \\
\hline Titania (UII) & 1.85 & 1.9 & c \\
\hline Oberon (UIV) & 1.74 & 1.8 & c \\
\hline
\end{tabular}




\section{Lander delta-V, Neptune's Moons}

\begin{tabular}{|l|r|r|r|}
\hline Moon & $\begin{array}{l}\text { Round-trip } \\
\text { delta-V (km/s) }\end{array}$ & $\begin{array}{l}\text { delta-V } \\
\text { Capability (km/s) }\end{array}$ & Sizing Category \\
\hline Naiad (NIII) & $\mathbf{0 . 0 6}$ & $\mathbf{0 . 0 6}$ & a \\
\hline Thalassa (NIV) & 0.08 & 0.08 & a \\
\hline Despina (NV) & 0.13 & 0.14 & b \\
\hline Galatea (NVI) & 0.17 & 0.18 & b \\
\hline Larissa (NVII) & 0.19 & 0.19 & b \\
\hline S/2004 N1 & & & \\
\hline Proteus (NVIII) & 0.44 & 0.50 & c \\
\hline Triton & 3.49 & 3.50 & d \\
\hline Nereid & 0.37 & 0.40 & c \\
\hline
\end{tabular}




\section{Lander delta-V, Neptune's Moons}

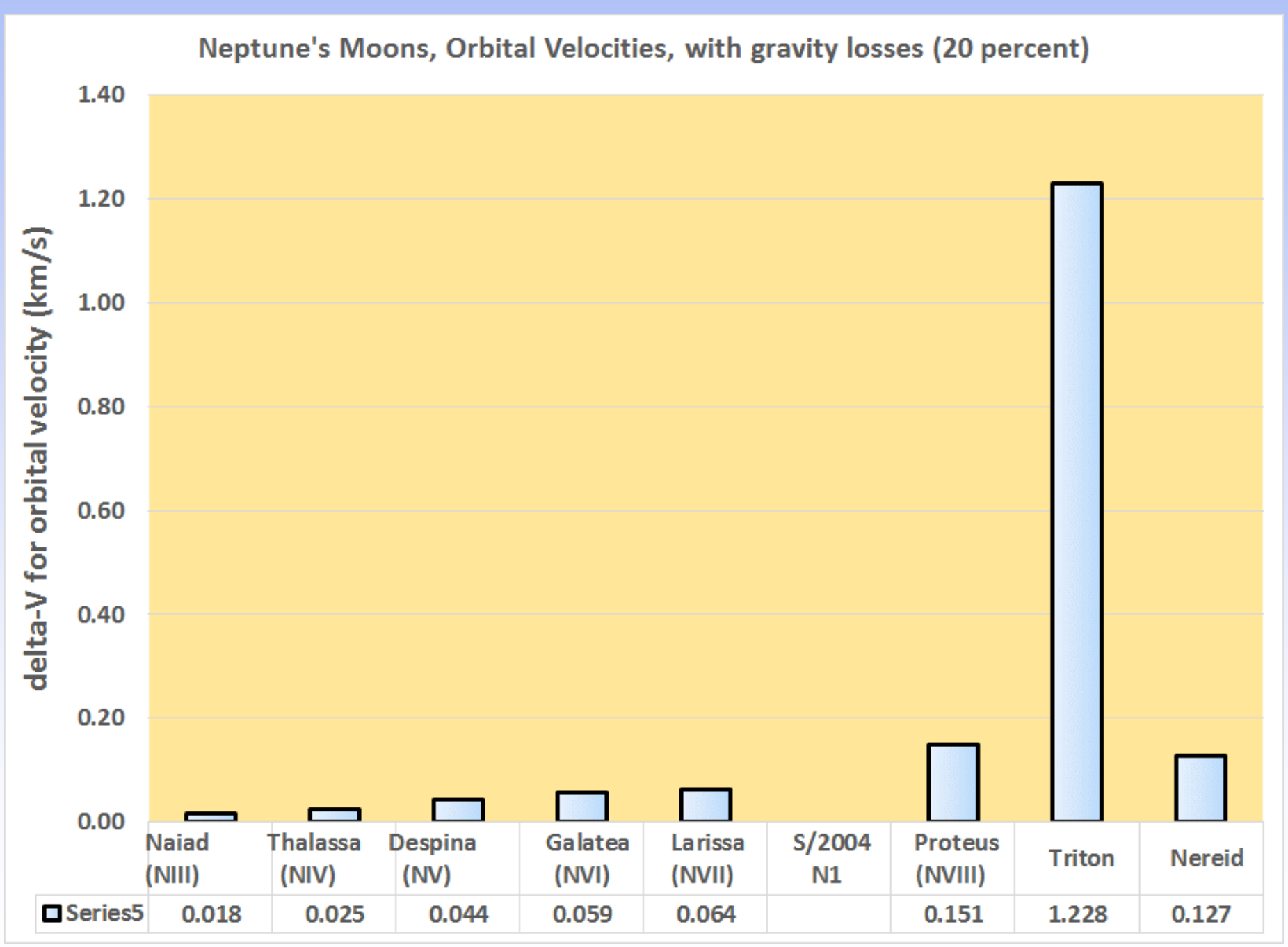




\section{Lander delta-V, Uranus' Moons}

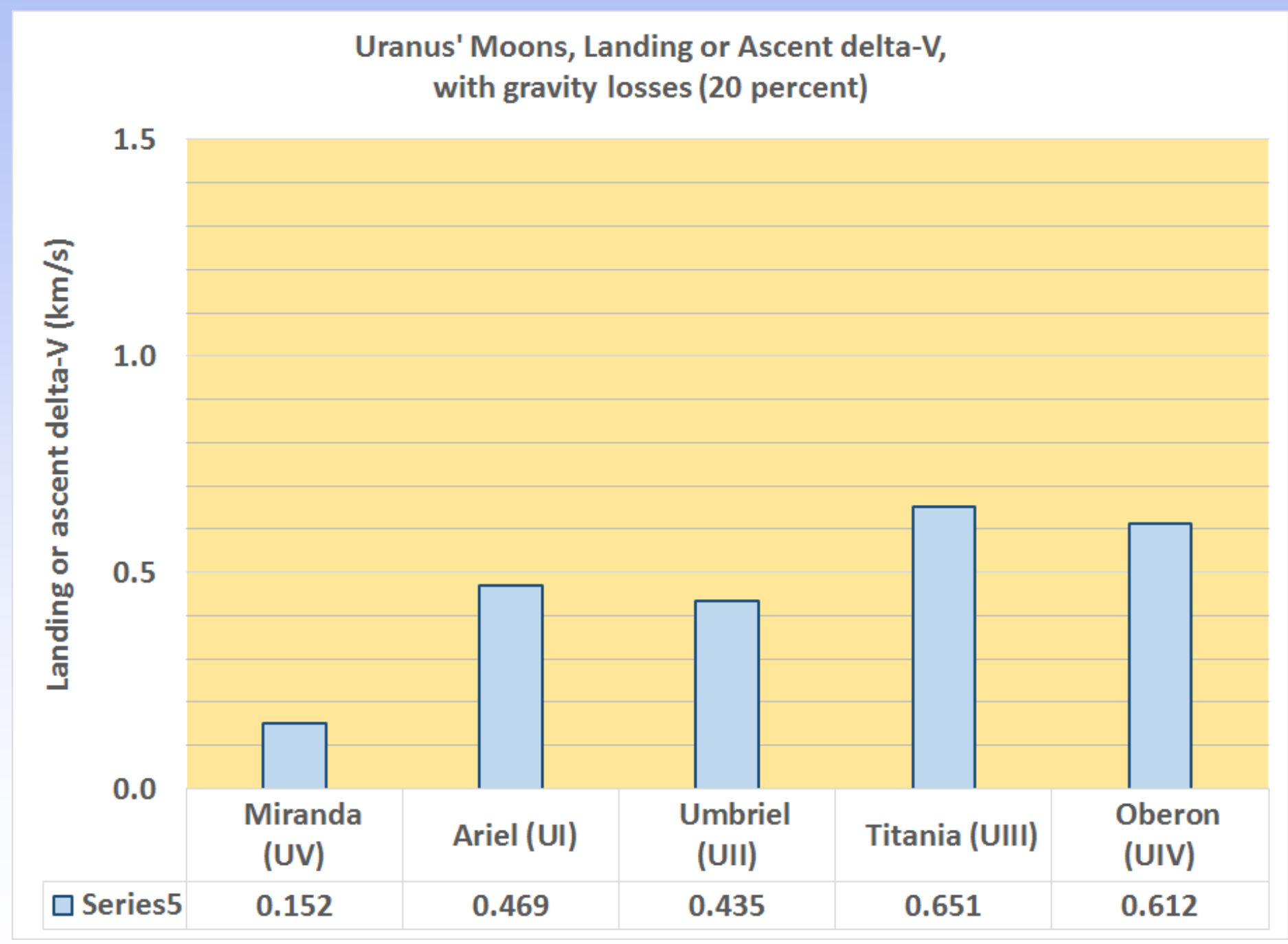




\section{"Optimizations"}

- Determine the best moon for operations.

- Is the smallest moon best?

- Does the smallest moon, with the lowest escape velocity, help in the optimization?

- Factory operations, lander fueling operations, and moon gravity level, for propellant and PPack factories may be the determining factors.

PPack = Physics package (NPP bomblets) NPP = Nuclear pulse propulsion 


\section{Outer Planet Moon G Levels}

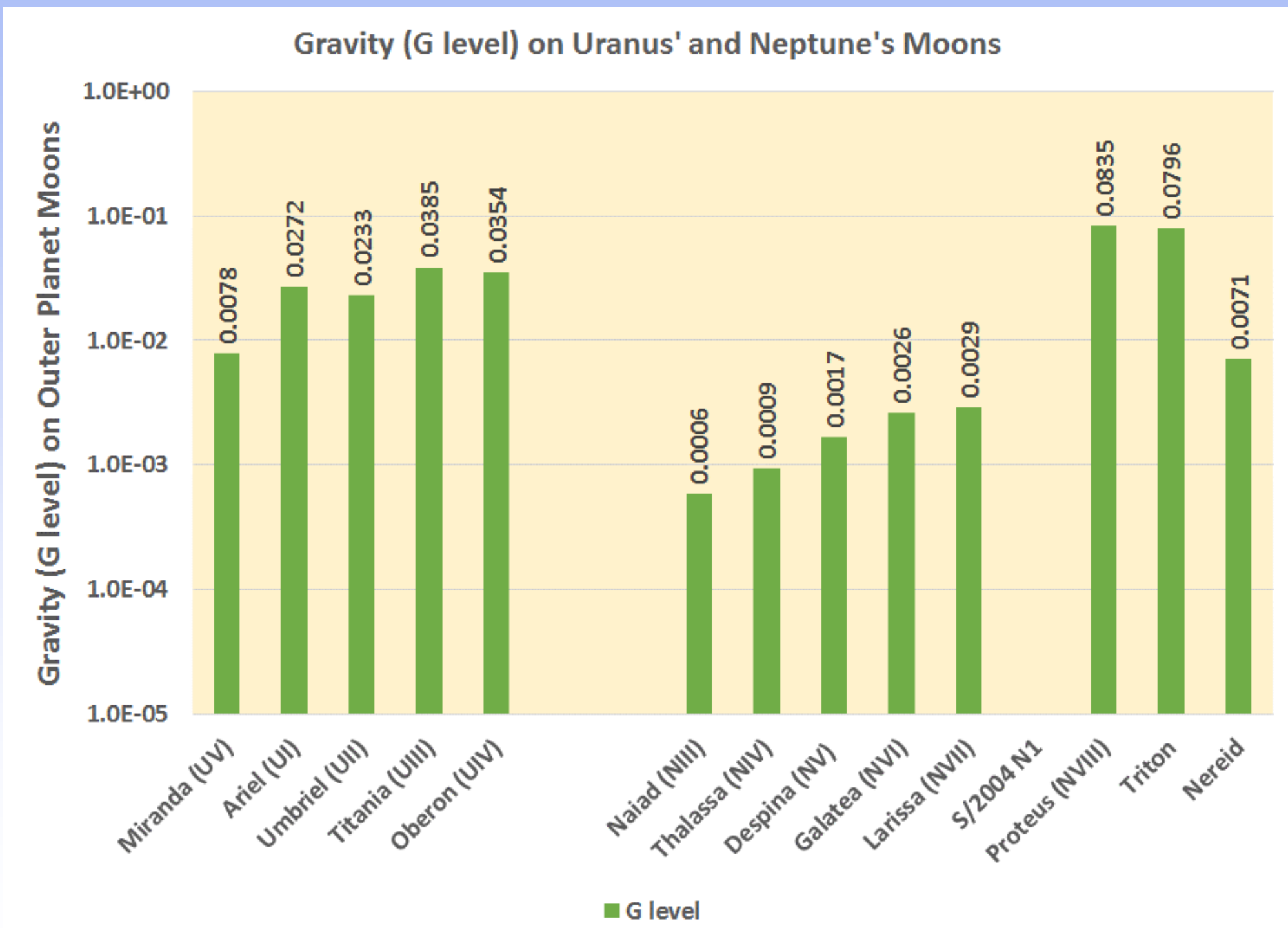




\section{Outer Planet Moon G Levels}

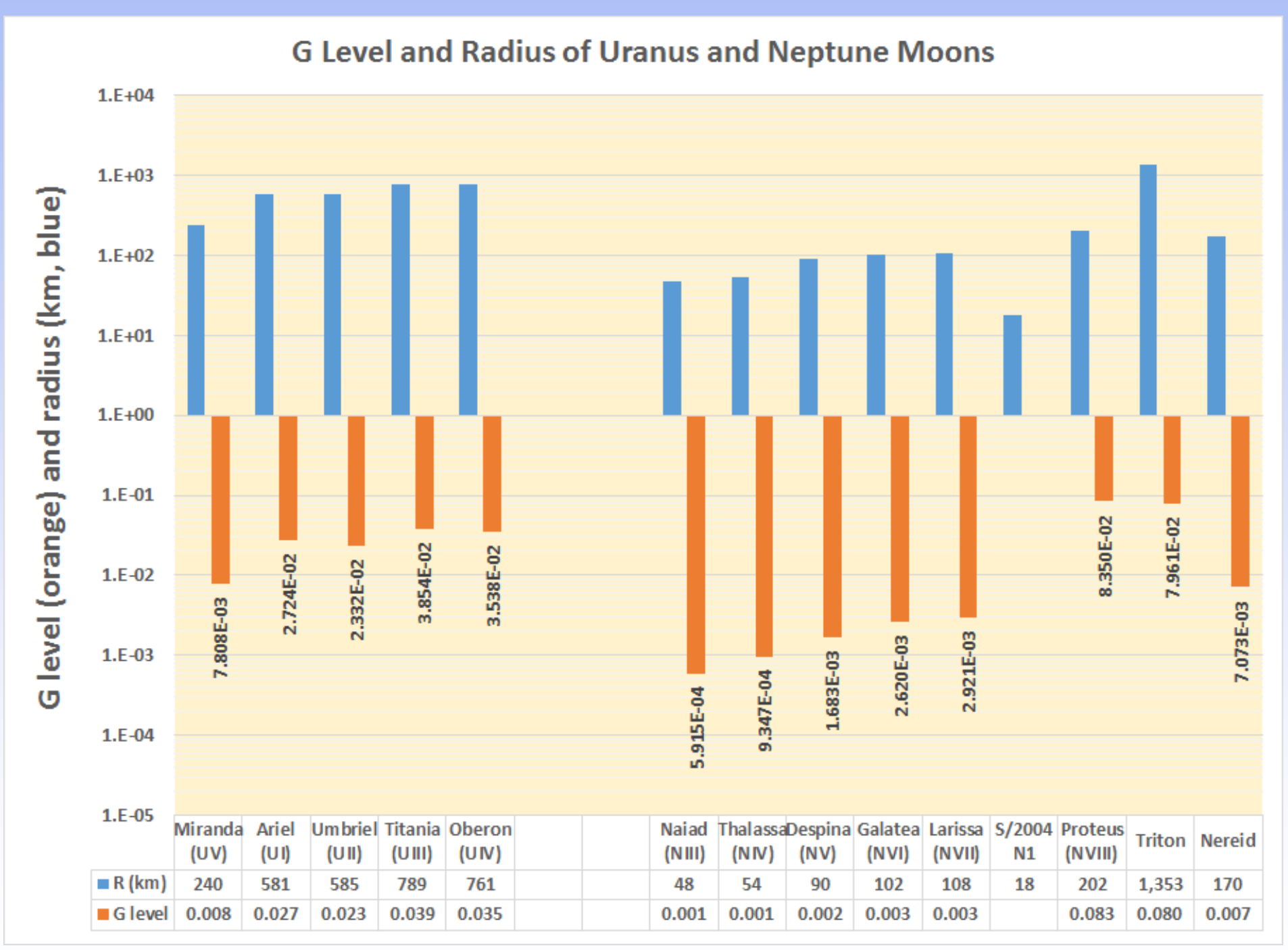




\section{Lander Design and Masses}

- The lander's mission is to deliver hydrogen to the OTV and return to the moon with the helium 3 or deuterium payload(s).

- The round trip delta-V would be based on each moon's escape velocity.

- As an example, a $0.5 \mathrm{~km} / \mathrm{s}$ delta- $\mathrm{V}$ value is needed for the moon, Miranda.

- Thus, the lander has the capability to reach escape conditions to rendezvous with the OTV.

- The lander was designed with an oxygen /hydrogen main propulsion system.

- The lander Isp was varied from $\mathbf{4 0 0}$ to $\mathbf{4 8 0}$ seconds. The dry mass scaling equation was:

- Mdry, stage $(\mathrm{kg})=$ Mdry, coefficient $\bullet M p(k g)$

- Mdry, coefficient $=0.4$ 


\section{Moon Lander Mass, Miranda}

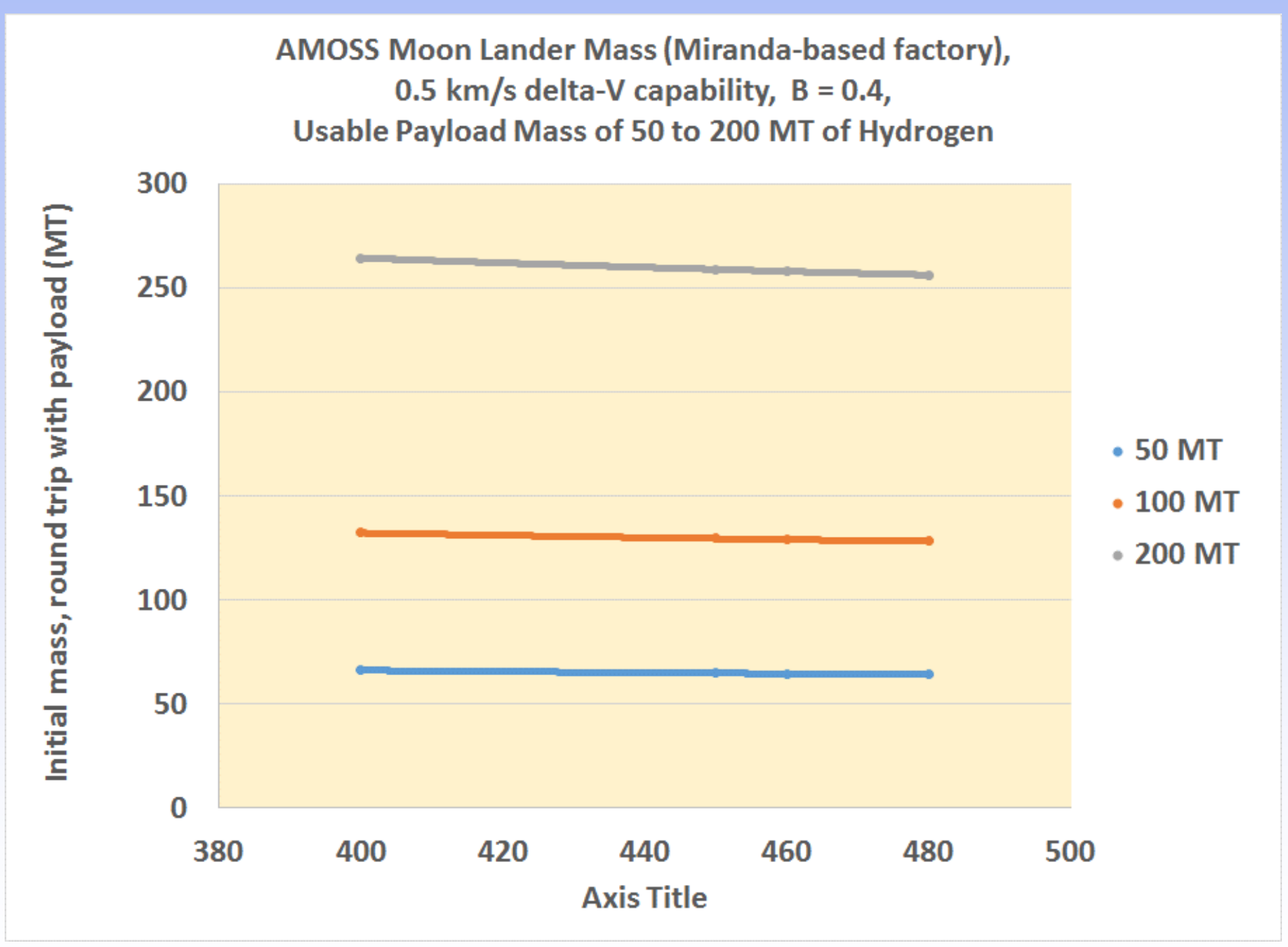


ISRU Factory Design Issues (need to update)

- The outer planet moons have low gravity levels.

- The gravity levels are similar to the disturbance accelerations of the ISS.

- Low gravity may require centrifuges for processing.

- The masses of the propellant factories must include mass estimates for low gravity operations.

- Cryogenic propellant processing and purification.

- PPack processing and assembly.

- Factory options.

- Lightweight factory (all external storage and processing),

- Heavy factory (also with external storage and processing), 


\section{Outer Planet Moon OTVs, Landers (1/2)}

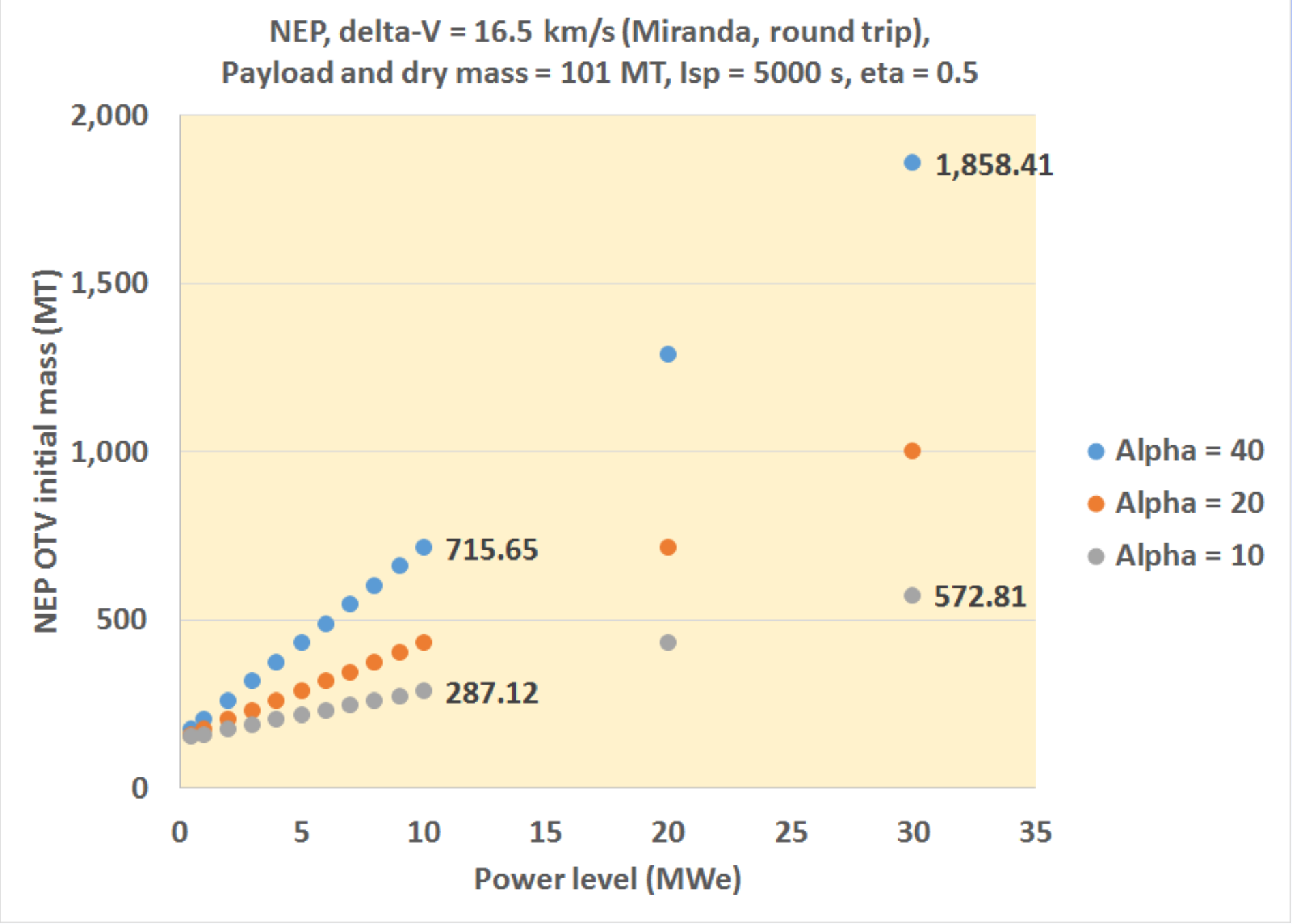




\section{Outer Planet Moon OTVs, Landers (1/2)}

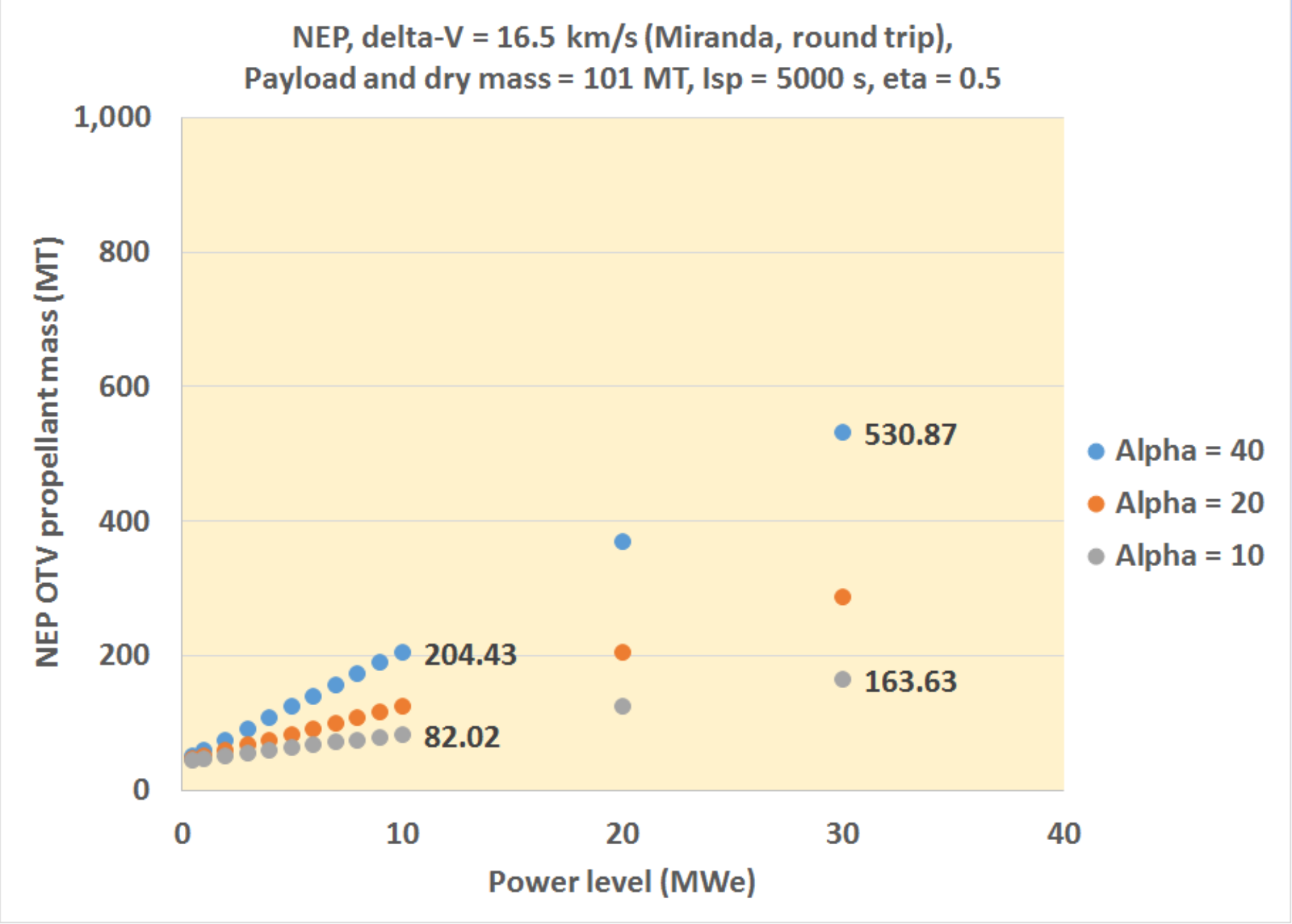




\section{Outer Planet Moon OTVs, Landers (2/2)}

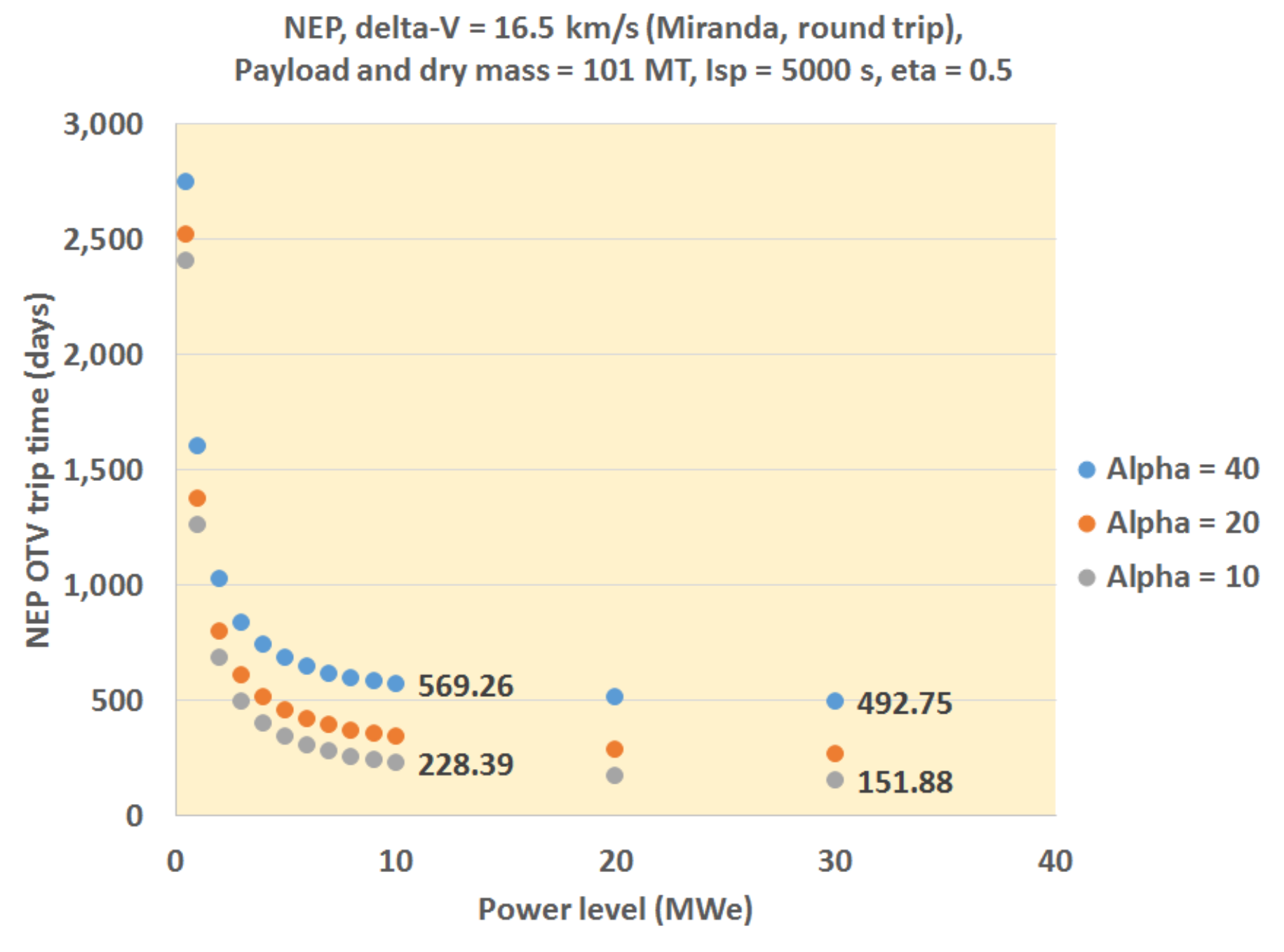




\section{Outer Planet Moon OTVs, Landers (2/2)}

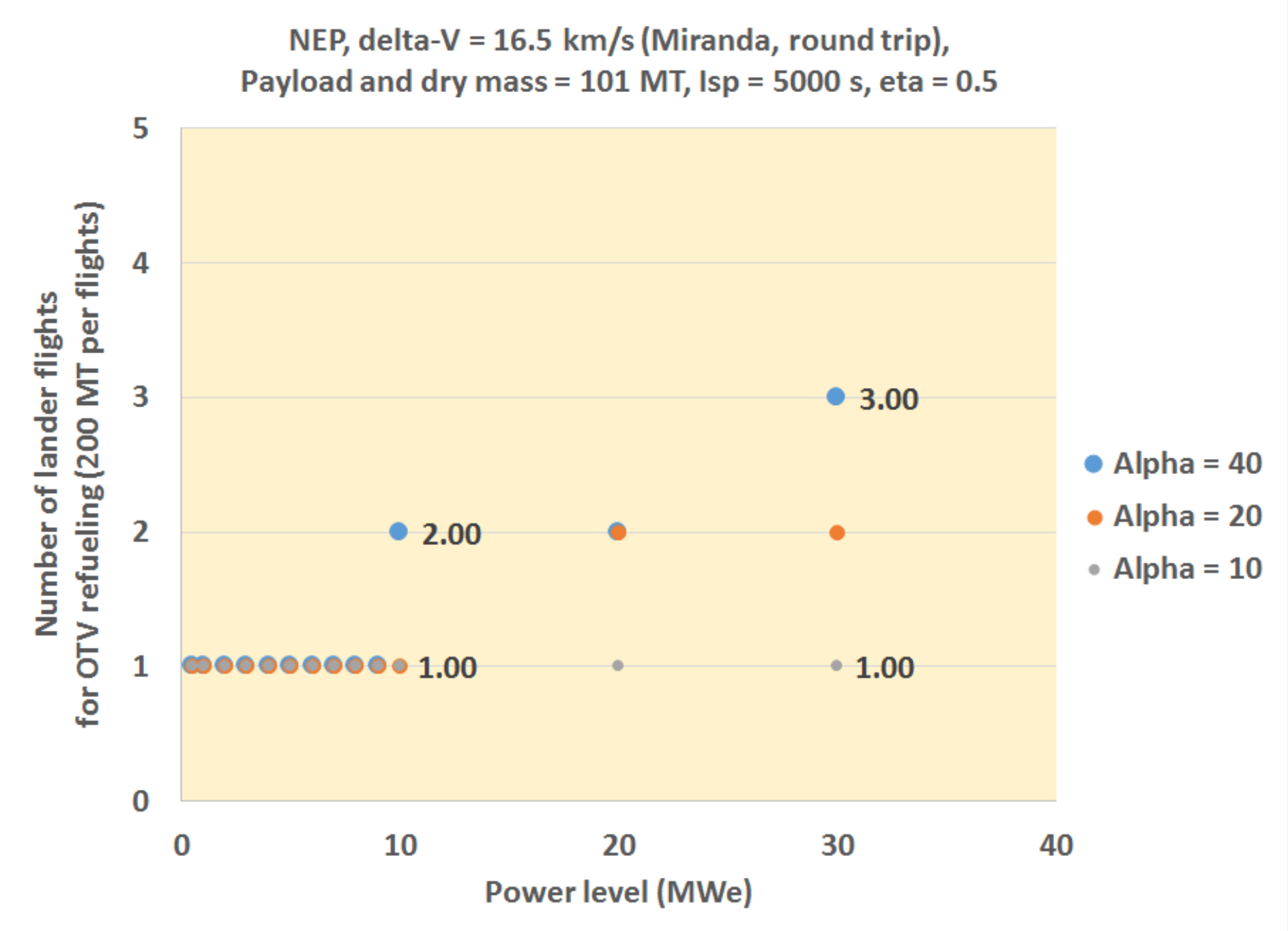




\section{AMOSS Moon Transportation Masses (1/2)}

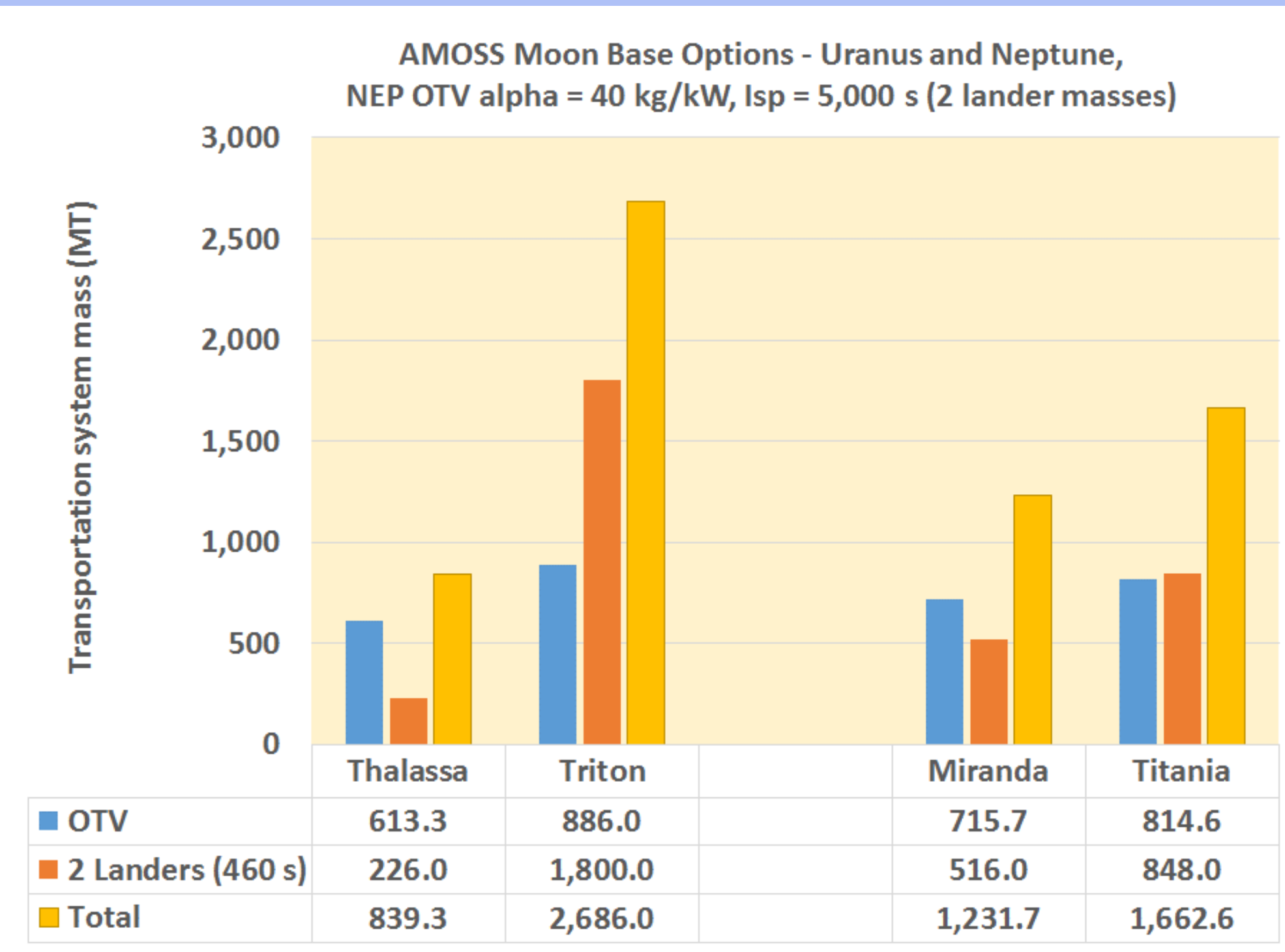




\section{AMOSS Moon Transportation Masses (2/2)}

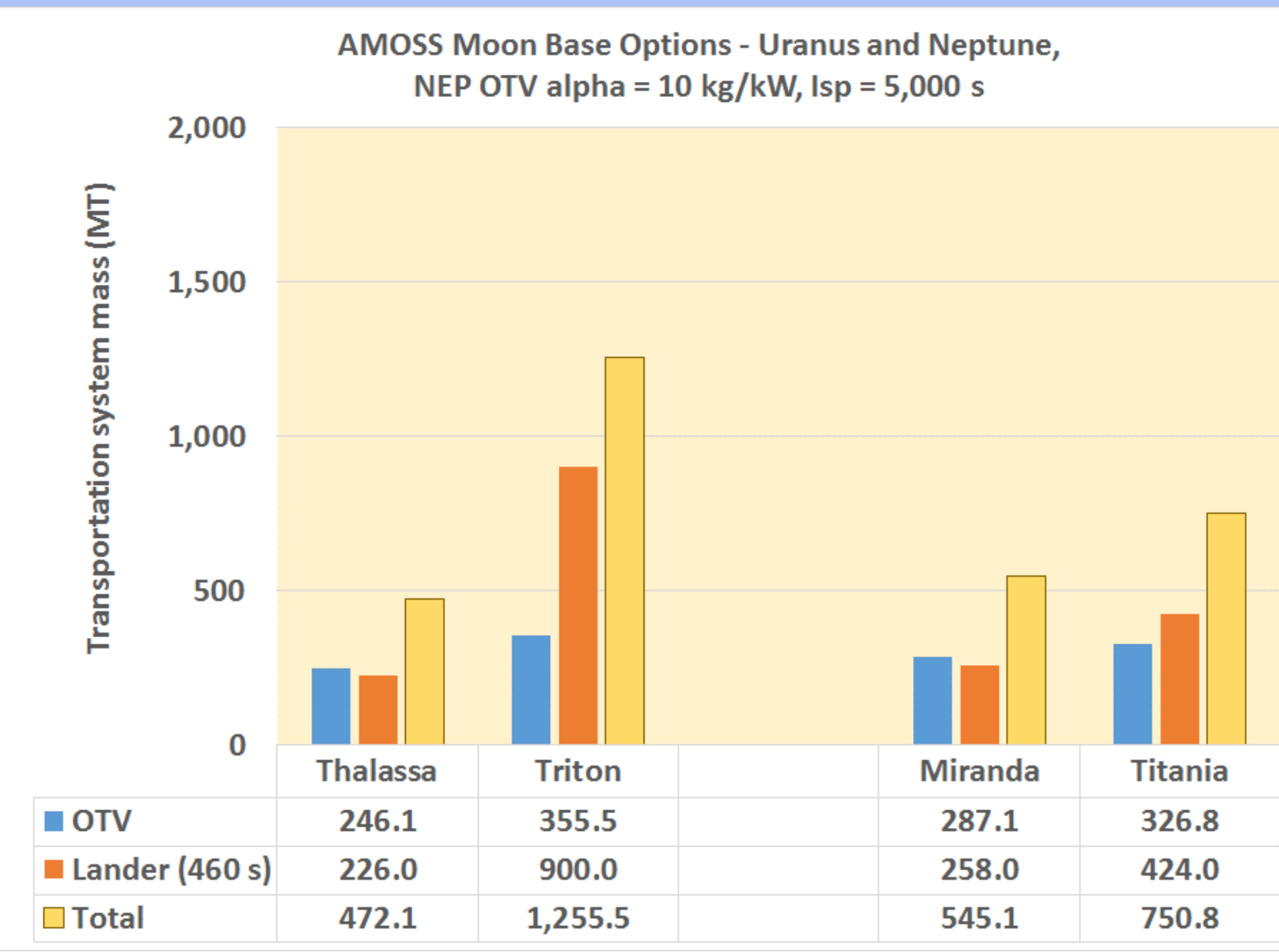


Preliminary Transportation Optimization (1/4)

- Establishing an optimum transportation system will be influenced by many factors: the OTV mass and power level, the payload mass of the lander and the selection of the moon for the mining factories.

- Several optima will be created based on the size and mass of the moon selected.

- The moon's mass will strongly influence the propellant mass needed for the refueling of its oxygen/hydrogen propulsion system and the time needed for creating the fuel for the OTV. 
Preliminary Transportation Optimization (2/4)

- With the OTVs, the 10 MWe power level appears to be the most acceptable.

- The initial mass of the OTV with power levels of 20 and $30 \mathrm{MWe}$ is too high, with no significant trip time benefits over the OTV at the 10 MWe power level.

- For the $101 \mathrm{MT}$ dry mass case, at $10 \mathrm{~kg} / \mathrm{kWe}$, and at 5,000 seconds of Isp, the trip time for the $30 \mathrm{MWe}$ level is 152 days versus 229 days at the 10 MWe level.

- With the $40 \mathrm{~kg} / \mathrm{kWe}$ case (with the same Isp and dry mass), the trip time at $30 \mathrm{MWe}$ is 493 versus $\mathbf{5 7 0}$ for the 10 MWe case. 
Preliminary Transportation Optimization (3/4)

- The OTV trip times are a significant issue.

- Many flight times are 100's of days.

- Initially, a single 1 MT payload of helium 3 or deuterium would fly on each OTV flight.

- Multiple helium 3 or deuterium payloads will have to be manifested on the OTVs.

- While the OTV and the lander can rendezvous at the moon's escape conditions, it may be more stable to conduct the propellant and payload transfers at a high moon orbit, but not at or beyond the moon's escape conditions. 
Preliminary Transportation Optimization (4/4)

- Lander payloads of 200 MT provide the minimal number of lander flights.

- The processing on the moon of the propellant, the propellant loading, and the cryogenic hydrogen payload loading may favor the largest payload capacity lander.

- With the 200 MT hydrogen payload, the number of lander flights needed to refuel the 21 MT dry mass $(5,000$ seconds Isp) OTV is 1 flight for the $10 \mathrm{~kg} / \mathrm{kWe}$ case and 2 flights for the $40 \mathrm{~kg} / \mathrm{kWe}$ case.

- Landers might be further optimized by increasing their payload capacity, which would further reduce the number of flights. 


\section{Concluding Remarks (1/3)}

- Using outer planet moon bases for mining propellants for OTVs and landers is an important option.

- Storing the AMOSS nuclear fuels away from the atmosphere will minimize the potential for unanticipated deorbiting of the orbiting storage facility.

- Using the moons for storage of the nuclear fuels and base of operations for OTV refueling is an excellent option.

- Though the gravity of these moons are much lower than that of Earth, that gravity will likely assist in any processes for mining and fuel processing. 


\section{Concluding Remarks (2/3)}

- The 10 MWe power levels for the OTV seems best for providing a relatively short trip time.

- The OTVs and landers will rendezvous near the escape condition of the small moon, shortening the trip time for the OTV (eliminating the need to spiral into low moon orbit).

- Larger landers (of 200 MT payloads) are more attractive than small landers, as the large landers require fewer flights to resupply the OTVs with fuel.

- The OTV trip times may be too long for effective use of the more distant moons. Moons that are closer to the planet may be required. 


\section{Concluding Remarks (3/3)}

- The gravity levels of the moons are very low.

- Therefore, artificial gravity may be needed to do effective ISRU processing.

- Processing in orbit may be more attractive for the PPack factories.

- Smaller moons that are closer to the planet require the lowest transportation system mass.

- The added complexity and mass of any large artificial gravity system may drastically change the optimization of any transportation system. 
Neptune, Go ISRU

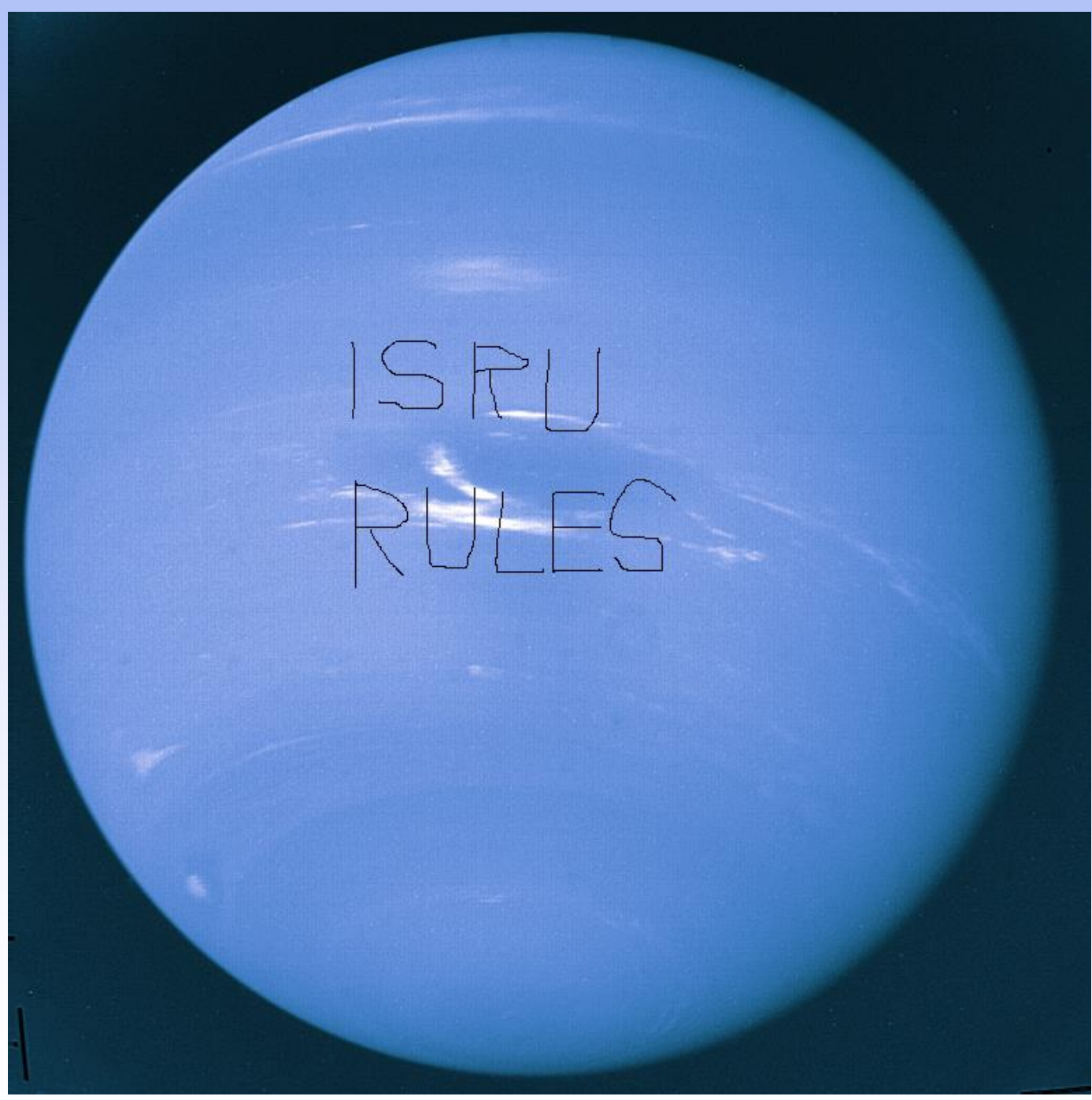

